\title{
Género, afectos y emociones en la literatura argentina del siglo $\mathrm{XIX}^{1}$
}

\author{
Natalia Crespo \\ UBA-Conicet
}

\author{
Q María Vicens \\ UBA-Conicet
}

En su libro Intimidades congeladas. Las emociones en el capitalismo, Eva Illouz propone pensar el siglo XXI como la era del achatamiento emocional, la mercantilización de los afectos privados y la sentimentalización de la esfera política. Disciplinar el afecto en nombre del capitalismo neoliberal trae aparejado, según Illouz, un capitalismo emocional. Al contrario de lo que ocurre en la actualidad, la literatura del siglo XIX (al menos, la que hoy pervive de él) cultiva la exaltación emocional para narrar un mundo moderno en construcción donde el sujeto está en el centro de la escena, de la mano del romanticismo, el individualismo burgués y el nacionalismo. En el caso argentino, esta exaltación tuvo particular arraigo: el protagonismo de las emociones en nuestros clásicos decimonónicos configura un imaginario nacional cruzado de pasiones y desbordes, sobre todo, políticos. Basta pensar en la imagen del joven unitario explotando de rabia en la casilla del matadero, ante la amenaza de una práctica de violencia sexual con la que se somete, amedrenta y humilla a los adversarios políticos, para entender hasta qué punto, en las emociones y sus excesos, se traman los conflictos, los sujetos y las identidades de nuestra literatura.

Si, como señala Sara Ahmed en The cultural Politics of Emotions (2004), la conformación de las comunidades nacionales depende en gran medida de una cohesión afectiva que se construye sobre la base de la identificación de ciertas identidades y cuerpos como enemigos internos y externos de esa comunidad, nuestro siglo XIX prueba la eficacia de esta idea en la recurrencia de esos "otros" que pueblan sus obras canónicas y movilizan los imaginarios de la patria. Gauchos, negros y negras, federales y federalas, inmigrantes, mujeres histéricas, frívolas, prostitutas; en cada etapa de ese siglo que va de la Colonia y la Revolución a la consolidación del Estado nacional y su crisis, nuestra cultura ha depositado en las subjetividades categorizadas como "extrañas" a la nación (y por ende, monstruosas) sus emociones negativas, aquellas

1Este dossier reúne algunas de las ponencias presentadas en el simposio coordinado por Mónica Szurmuk (UBA/UNSAM/Conicet) "Afectos y literatura en el siglo XIX: lecturas alrededor de En clave emocional de Ana Peluffo", que tuvo lugar en noviembre de 2018 en el marco del IV Simposio Internacional Pensar los afectos/ Thinking Affect, organizado por el Núcleo de Estudios Sociales sobre la Intimidad, los Afectos y las Emociones (FLACSO-Argentina) y por el Seminario permanente de estudios sobre género, afectos y política (SEGAP), de la Facultad de Filosofía y Letras (UBA). 
que se expulsan del imaginario emocional compartido, y las ha reelaborado en clave ficcional a través de clásicos como Facundo, Amalia, Martín Fierro, La gran aldea, En la sangre, La bolsa. Lejos de ser una novedad, la idea de que "el otro" es una figura nodal, tanto en la literatura como en la configuración misma de "lo nacional" y en el ideario de los letrados que lo consolidan, es uno de los pilares de nuestra crítica, de David Viñas y su Literatura argentina y realidad política (1964) en adelante, que se entrecruza a su vez con el devenir de la crítica latinoamericana. En este sentido, los estudios vinculados con el llamado "giro afectivo" operan como nueva caja de herramientas críticas capaz de interpelar, una vez más, a nuestros clásicos, así como a la historia crítica entramada alrededor de ellos.

En su presentación a El lenguaje de las emociones: afecto y cultura en América Latina (2012) - tomo editado por Mabel Moraña e Ignacio Sánchez Prado, que implicó en su momento una intervención crítica sustancial, tanto por su carácter colectivo, como por su capacidad de mapear nuevas líneas de análisis para abordar la producción cultural del continente-, Sánchez Prado destaca el potencial revitalizador de los que denomina "los lenguajes críticos del afecto, la emoción y la sentimentalidad". Provenientes de paradigmas distintos e incluso contradictorios, estos lenguajes podrían "recalibrar" los estudios culturales - más allá del privilegio epistemológico otorgado a la ideología y a las identidades sociales - para "superar distintos impasses generados por la institucionalización de los discursos originalmente concebidos como disidentes" (2012: 12) y volver a concentrar la mirada en esos nudos de resistencia de nuestra cultura que disparan interrogantes y nuevas miradas.

Si bien en las últimas décadas, aportes como los de Judith Butler y Rossi Braidotti han sido fundamentales en la desconstrucción del sistema sexo-género y en la visibilización de los dobleces, fisuras y desvíos que fragmentan las visiones unívocas y esencialistas sobre el género, estos lenguajes críticos del afecto, las emociones y la sentimentalidad proponen una nueva flexión - en términos de Sylvia Molloy-sobre la cultura (argentina en este caso). Cuestionan sus binarismos a partir de la teoría, sí, pero también, de una mirada atenta a los diversos modos en que los vínculos y la sensorialidad cifran sentidos en los textos. Se trata de pensar cómo una comunidad construye en cada época un sensorio compartido por los sujetos, los imaginarios y los cuerpos, un sensorio posible de entramar - según Francine Masiello en The Senses of Democracy Perception, Politics, and Culture in Latin America (2018) - en el entrecruzamiento de textos, obras de artes, voces y otras experiencias sensibles.

Siguiendo a Masiello, podríamos preguntarnos entonces: ¿cuál es el sensorio o los sensorios de la Argentina del siglo XIX?, ¿cómo se traslucen en sus producciones literarias?, ¿a quiénes involucran para la conformación de la comunidad?, e incluso plantearnos: el hecho de que las mujeres hayan sido consideradas históricamente el género "sensible", ¿las posiciona de un modo diferente ante este proceso? Porque, tal vez, es gracias a la exaltación emocional que la literatura argentina del siglo XIX pudo construir lo que Barbara Rosenwein ha definido en Emotional Communities in the Early Middle Ages como "comunidades emocionales", es decir, imaginarios compartidos que se rigen por códigos afectivos específicos donde se entronizan ciertos sentimientos y se reprimen otros para fortalecer los vínculos de ciertos grupos sociales.

En este mundo decimonónico, polarizado por dualismos (razón y emoción, lo público y lo privado, el campo y la ciudad, la colonia y la república, civilización y barbarie), se van a imponer los "estados del alma" fuertemente heteronormativos (el enamoramiento heterosexual, la libido masculina, el amor maternal), pero no solo ellos. También asoman sentimientos "negativos" altamente prestigiosos: el dolor, la angustia, la melancolía, el splin se presentan como emociones dignas de ser exaltadas - sobre todo dentro del horizonte estético del romanticismo- en contraposición con otros 
fuertemente censurados, a veces identificados con personajes femeninos, como la rabia, los celos, la envidia o la agresión.

Ahí está para probarlo la galería de villanas de nuestra literatura, desde la grotesca Doña Josefa, secuaz de Rosas, líder de las negras y sirvientas que cierran las filas de la chusma federal, a la envidia encarnada ante el amor de Amalia y Eduardo; Medea, esa matrona antimaternal y monstruosa que humilla a la protagonista de La gran aldea y se pasea de tertulia política en tertulia política alabando al general Mitre; o Clara, protagonista de La bolsa de huesos, la primera asesina serial de nuestra literatura, cuyos "excesos pasionales" (por el cuerpo del otro y, también, por el saber del otro) la llevan al crimen y al suicidio. Como las feministas que analiza Sara Ahmed en The promise of Happiness (2010), todas estas villanas tienen dos rasgos en común: encarnan emociones antinormativas ( $y$, como tales, excesivas) y estas se vinculan con la trasgresión de pretender ocupar ámbitos masculinos de poder, política y ciencia.

En este sentido, la literatura argentina del siglo XIX puede leerse como una enciclopedia de las emociones y sentimientos que configuraron a los sujetos de la patria y que, a veces, sorprende en los usos y alianzas que propone. Las lágrimas, como ha señalado Ana Peluffo en En clave emocional (2016), cifran la eficacia del sentimentalismo en la creación de imaginarios empáticos, que conectan el llanto de Sarmiento ante las enseñanzas de sus maestros coloniales en Recuerdos de provincia con el de Martín Fierro ante la muerte de Cruz, trazando comunidades homosociales separadas en el tiempo y entre sujetos tan distintos entre sí, incluso enemigos. Los "excesos pasionales", en cambio, excluirán a los sujetos de la comunidad imaginada, ya sean adversarios políticos, gauchos rebeldes o mujeres arrastradas por el deseo. Y en ese mapa de emociones, no solo se juega la constitución de la literatura nacional, sino también la configuración simbólica de los sujetos femeninos y masculinos que requería la biopolítica del patriarcado para solventar su modelo republicano y liberal.

¿Cómo entender hoy ese exceso afectivo que recorre la producción cultural del siglo XIX? En su libro, Peluffo señala con lucidez el efecto distanciador que provocan estos textos en lxs lectorxs contemporánexs, ya que "dado que muchos artefactos decimonónicos estetizan emociones que causan incomodidad en el presente (la tristeza, el ennui, la compasión, el odio) leemos este material con más desconfianza que interés". Partir de esta desconfianza (desconfiar de ella, si se permite la redundancia) para indagar en torno a los múltiples significados y usos de lo afectivo/lo sentimental en ciertas construcciones sexo-genéricas de la literatura decimonónica es el objetivo de este dossier.

¿Qué sentimientos aparecen recurrentemente en estos textos?, ¿cómo son estetizados y para qué?, ¿cuáles son acatados y cuáles criticados en cada escrito y por qué?, ¿de qué modo esas narrativas decimonónicas reproducen o desestabilizan, a partir de su particular configuración de lo sentimental, los binomios con los que tradicionalmente se ha enfocado esta literatura? ¿Qué otros discursos (socio-religiosos, políticojurídicos, etc.) subyacen en el entramado de cada una de estas escrituras y cómo se negocia con ellos la construcción de los géneros? Estas son algunas de las preguntas que articulan los ensayos aquí reunidos, un corpus crítico que trabaja a partir de diversos materiales - cartas, periódicos, archivos judiciales y, también, novelas-para encontrar nuevos problemas, comunidades, imaginarios en la producción cultural decimonónica. Estos corpus no centrados exclusivamente en los clásicos permiten moverse, al mismo tiempo, dentro y fuera del canon.

Frente a estos interrogantes, y a modo de introducción, le pedimos a Ana Peluffo una versión adaptada de la apertura de En clave emocional, el libro que inspiró la idea inicial de este dossier: "Pensar el siglo XIX desde los afectos" traza un recorrido de 
los principales aportes teóricos del giro afectivo (Sara Ahmed, Brian Massumi, Peter Stearns) y de lxs historiadorxs de la emoción (Barbara Rosenwein, William Reddy) para ver de qué manera una aproximación desde esta perspectiva sobre los textos decimonónicos nos puede servir para desestabilizar, subvertir y/o complementar lecturas canónicas muy arraigadas en el imaginario crítico. A partir de esta historización de los afectos, Peluffo se centra en la racialización y feminización de las emociones para pensar específicamente la politización del sentimentalismo y la necesidad "de recobrar formas de leer el lenguaje no referencial del afecto que hemos perdido en el siglo XXI".

El ensayo de Natalia Crespo, "Vamos, déjese querer. Afecto, emociones y red en cartas de escritores rioplatenses (1837-1852)", recorta un corpus de cuarenta cartas escritas por los intelectuales románticos de la Generación de 1837 (e incluidas en el Archivo del Dr. Juan María Gutiérrez) y lee en ellas cómo se prestigian determinados sentimientos dentro de esa "comunidad emocional". A partir de algunas nociones del llamado "giro afectivo" (Sara Ahmed, Barbara Rosenwein, Leonor Arfuch, Cecilia Macón, Ana Peluffo) y teniendo en cuenta el concepto de redes intelectuales (Claudio Maíz, Álvaro Fernández Bravo), Crespo indaga en torno a los roles, opositivos y sistémicos, de algunos miembros de esta comunidad y en torno a los usos y gestos con que cada uno refiere el afecto. La construcción de alianzas homosentimentales, la estetización del dolor del exilio, el recíproco control y la retórica del afecto para fines de prensa literario-política, son algunas de las recurrencias en este corpus de escrituras privadas pero sociales que, aunque de narradores célebres (Juan María Gutiérrez, Esteban Echeverría, José Mármol, Domingo F. Sarmiento), permanecen aún hoy poco transitadas por la crítica.

En el doblez de esta comunidad afectiva de emigrados del rosismo, Vanesa Miseres propone, en "Femicidio y emociones en la Argentina rosista: el caso de Paulino Rojas y Encarnación Fierro", una mirada histórica sobre el tratamiento y la visibilidad social de ambos términos. El ensayo se enfoca en el juicio al militar Paulino Rojas, integrante del Regimiento de Granaderos a Caballo y partícipe de la campaña libertadora del Perú, por la muerte de su esposa, Encarnación Fierro. Tomando como eje algunas conceptualizaciones teóricas sobre el papel de las emociones en el siglo XIX latinoamericano (Laura Podalsky, Mabel Moraña e Ignacio Sánchez Prado, Ana Peluffo), Miseres analiza los argumentos utilizados en las acusaciones contra Rojas y la defensa de su abogado, Valentín Alsina, que parten del plano emocional y someten a escrutinio público tanto los "desvíos amorosos" y pasiones desmedidas de la víctima - provocadas, se especula, por lecturas románticas-, como los celos de un hombre que, en última instancia, busca defender su honor y reputación en el panteón de héroes nacionales. En este sentido, el caso permite entender algunas relaciones, jerarquías y alianzas interpersonales (militares, amorosas, familiares, de amistad) del período rosista, el valor de las emociones en la construcción de los sujetos en el siglo XIX y el impacto de las mismas en el ejercicio de la ciudadanía y los derechos, aún en pugna, de las mujeres.

Claudia Torre avanza en el siglo XIX para reflexionar en torno a la figura de la espera y sus diversas inflexiones en el ensayo "La espera íntima y estatal, en las obras de los hermanos Eduarda y Lucio Mansilla". Partiendo de la idea de Roland Barthes en Fragmentos de un discurso amoroso de la espera como un tumulto de angustia, con una escenografía organizada y manipulada, Torre propone leer esta figura en la encrucijada de la intimidad y la trama social. Se detiene en los matices diferenciales que presentan Eduarda Mansilla en El Médico de San Luis (1860), y Lucio V. Mansilla en Una excursión a los indios ranqueles (1870). Publicados como folletines del diario La Tribuna, los dos textos refieren, a partir de la idea de una narración pública que rodea y se filtra sobre las formas y prácticas de la vida cotidiana y de las historias de familia, esta 
pasión/sujeción como un núcleo narrativo que determina las acciones de ese médico extranjero de provincia que espera al hijo descarriado por la montonera federal y del coronel del Ejército argentino que decide abandonar la espera de la autorización castrense para internarse tierra adentro.

Finalmente, el trabajo de María Vicens, "Imaginarios de amistad, autoría y deseo: la figura de la escritora en la prensa argentina del 80", indaga las poses e imágenes a partir de las cuales las escritoras argentinas se legitimaron mutuamente en la esfera pública, configurando un imaginario específico en torno a la sororidad letrada. Pero esta construcción centrada en el mundo de afectos idealizados y feminizados también muestra sus fisuras y puntos de fuga en las secciones "subalternas" de los periódicos para mujeres donde ellas escriben: en las "zonas frívolas" de estas publicaciones (las columnas de moda y crónica social y las misceláneas) circulan emociones y gestualidades antinormativas para el deber ser femenino de la época (gritos, enojos, reclamos, pero, también, deseos y ambiciones) que operan como doblez de esa comunidad afectiva, abriendo el espacio de la prensa a nuevas voces y tonos femeninos.

Tanto por las fuentes y textos trabajados como por el modo de abordarlos, los trabajos reunidos en este dossier se proponen hacer nuevas preguntas y delinear nuevos recorridos en torno a las construcciones de masculinidades y feminidades en la literatura argentina del siglo XIX, a partir de sus lecturas "en clave emocional", y sugerir líneas de análisis que se conecten, a su vez, con una cartografía más amplia de afectos y comunidades. Porque es en esa exaltación emocional y en la posibilidad que tenemos hoy, a la distancia, de indagar en sus configuraciones y sentidos, donde podemos encontrar nuevos modos de abordar la literatura argentina del siglo XIX. 


\section{Q Bibliografía}

»Ahmed, S. (2004). The cultural Politics of Emotions.

»----. (2010). The promise of Happiness.

» Illouz, E. (xxxx). Las emociones en el capitalismo.

»Masiello, F. (2018). The Senses of Democracy Perception, Politics, and Culture in Latin America.

»Moraña, M. y Sánchez Prado, I. (eds.) (2012). El lenguaje de las emociones: afecto y cultura en América Latina.

»Peluffo, A. (2016). En clave emocional.

» Rosenwein, B. (xxxx). Emotional Communities in the Early Middle Ages.

»Viñas, D. (1964). Literatura argentina y realidad política. 